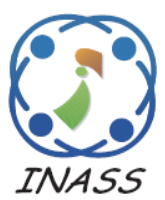

\title{
Torque Ripple Minimization in Switch Reluctance Motor Drives: an ANFACO Based Control
}

\author{
Megha Chaple $^{1 *} \quad$ Sanjay Bodkhe $^{1} \quad$ Prema Daigavane $^{1}$ \\ ${ }^{I}$ G. H. Raisoni College of Engineering, Nagpur, India, \\ *Corresponding Author Email: meghachaple0707@gmail.com
}

\begin{abstract}
In this paper, the torque ripples in the switched reluctance motor (SRM) is constrained by utilizing an Ant Colony Optimization and an Adaptive Neuro Fuzzy Inference System (ANFACO). The control scheme is utilized for the simultaneous control of the speed and current of the SRM which fuses two controlling loops of PI controller. The external loop is governed for speed control and the internal loops is governed for current control despite the ideal decision of the turn on and turn off switching angles. With respect to, for instance, speed, current, inductance and torque, the dynamic behavior of the SRM is examined to control the speed and current which restrict the torque ripple. The gain parameters of the PI controller are ideally made as the dataset by the ant colony optimization (ACO) algorithm. The created dataset is passed to the adaptive neuro fuzzy inference system (ANFIS) for the error prediction. By then, the proposed framework is executed in the MATLAB/Simulink working stage. The execution of the proposed method is affirmed by differentiating and the current systems like ant lion optimization (ALO), non dominating sorting search algorithm (NSGA-II) and combined moth flame optimization and genetic algorithm with recurrent neural network (CMFG-RNN) procedures.
\end{abstract}

Keywords: Switch reluctance motor, Torque ripple, ACO, ANFIS, PI controller, Flux, Speed and current controller.

\section{Introduction}

Electrical Drives (EDs) are very important part in an industry to replace a human operator for handling different processes and machineries to meet a comfortable efficiency. The necessity of EDs mainly depends on the accessible mains and load characteristics for the particular application [1]. For such application, the study of Switched Reluctance Motor Drives (SRMDs) has done a more interest [2, 3]. SRMDs are used in household applications, hybrid and electric vehicles, wind power plant, aeronautical and aircraft applications, etc., The advantages of SRMDs are simple structure, less cost for manufacturing and reliability capability, high degree of self determination between phases, short end-turn, low inertia and operate in hard environment $[4,5]$. Generally, SRMD is a doubly salient pole machine, and mainly based on the concept of variable reluctance. The phases are energized over the entire region of rising inductance and the active current limiting from the controller at low speeds. SRMDs are only depending on the variation of inductance is rising or falling due to angular position (non-linear) but it does not dependent on the direction of the current $[6,7]$. So, for an optimal excitation sequence, the control structure requires rotor position.

The main drawback of SRM drives are high torque ripple which causes vibration and acoustic noise $[8,9]$. To reduce the torque ripples, various control schemes are derived to the inverter of the SRMDs along with rotor position tracking [10 - 12]. Two control strategies are accomplished in this scenario: 1.Voltage Pulse Width Modulation (PWM) for adjusting the motor speed 2. Regulating the advanced firing angles as a function of the appropriate motor speed [13]. The most difficult thing to control in SRMDs it has highly non linear and dynamical behavior [14]. In this work, the control scheme of ANFACO is used for controlling the speed of SRM with torque ripple minimization. 
In the proposed control sheme, the torque ripple of SRM is minimized by controlling the current profile and the optimal selection of turn on and turn off switching angles. Here, the optimal gain parameters are generated by ACO technique and ANFIS technique is utilized to optimally predict the gain parameters of the PI controller. By utilizing the proposed technique, the torque ripples are greatly minized with optimal turn on and turn off switching angles. The proposed method is obviously depicted in detail. The rest of this article is composed as takes after, the current research work and the foundation of the exploration work is talked about in Section 2. The proposed procedure careful clarification is clarified in Section 3, 4 and 5. The proposed method accomplishment comes about and the related discourses are given in Section 6 and the paper is finished up in Section 7.

\section{Recent research works: A brief review}

Various research works have already existed in literature which depended on the torque ripple minimization of SRM utilizing different techniques and different perspectives. N. Saha et.al. [15] has suggested a Hybrid Many Optimizing Liaison Gravitational Search Algorithm (Hybrid MOLGSA) technique for simultaneous control of the speed of SRM and for minimizing the torque ripple. However, the implemented technique is easy to fall into local optimum and has low solution precision for complex optimization problems. A novel control strategy based on the distractive interference in the torque ripple for SRM has been presented by C. Labiod et. al.[16]. The special SRM model was implemented according to the presented strategy; the reference torque was divided into two symmetrical torque references and treated by hysteresis controller. The presented method has the drawbacks of variable switching frequency results in difficulty in designing input filter.

X. Deng et. al. [17] has established a control method for controlling the torque ripple using sixphase SRM drives. By regulating the rotational speed of the stator flux linkage, a constant instantaneous torque was obtained. However, it requires complex switching rules for smooth torque generation during commutation. H. Zhang et. al. [18] has illustrated a level set method to optimize the rotor poles of a four-phase 8/6 SRM were introduced for minimizing torque ripple. Although the presented method provides a good closed-loop control performance, it requires a large amount of computational burden for the algorithm execution.
C. Li et. al. [19] has explored a model predictive torque control algorithm based on a finite control set approach for an SRM drive. Despite such algorithm provides effective solutions for solving complex optimization problems, its results are still unsatisfactory. Along these lines, the checked on techniques detriments and extent of building up a basic structure of controller for SRMDs frameworks have roused me to do this exploration work.

\section{Torque ripple minimization for SRM drive}

When there is a variable machine co-energy, the torque ripple get emerges which thus causes the variety of stator flux linkage, excitation current and rotor position. Because of the adjustment in position of the rotor and phase current, the flux leakage inductance and torque get to a great degree coupled and ends up nonlinear. Henceforth, by controlling the current and appropriate choice of turn on and turn off angle will prompts diminishment in the torque ripples. Since it relies upon the rotor position and the reference current this in turn relies upon the speed of the motor and the estimation of load torque. Here, another combination method is proposed to get the speed control with reduction in torque ripple of SRM. The proposed control procedure incorporates speed control, current control alongside turn on and turn of switching angles. The proportional and integral gains of both speed and current controller and turn on and turn off angles are ideally decided. These ideal blends of the gain parameters can lessen the torque ripple and henceforth enhance the execution of the SRM drive [20],

$$
T_{\text {rip }}=\frac{T_{\text {rip }}^{\max }-T_{\text {rip }}^{\min }}{T_{\text {rip }}^{\text {mean }}}
$$

Where, the maximum, minimum and mean values of the total torque is meant as $T^{\text {max }}{ }_{r i p}, T_{r i p}^{\text {min }}$ and $T_{r i p}^{\text {mean }}$.

\section{Designing of proposed controllers}

The optimal estimations of proportional and integral gains of both speed and current controller with the turn on and turn off switching angles is the control component gave by the proposed framework. The proportional and integral gains are for the most part used to give a general control action which is relative to the error signal and to decrease the steady state errors through low frequency compensation by 
an integrator individually. These gains are improved by the proposed PI controller comprises of the speed and current controller. The speed error signal is the contribution of the speed controller i.e., the deviation between the actual and the reference speed. The error measurement of both speed and current can be calculated using the integral squared error (ISE) of speed $I S E_{\text {speed }}$ and current $I S E_{\text {crnt }}$ which is computed as,

$$
\begin{aligned}
I S E_{\text {speed }} & =\int_{0}^{\infty}\left(\omega_{\text {ref }}-\omega_{\text {act }}\right)^{2} d t \\
I S E_{\text {crnt }} & =\int_{0}^{\infty}\left(I_{r e f}-I_{p h}\right)^{2} d t
\end{aligned}
$$

Where, $\omega_{\text {ref }}$ and $\omega_{a c t}$ represents the reference and actual speed, $I_{r e f}$ and $I_{p h}$ represents the reference and phase current.

The PI controllers are connected in parallel to each phase and the transfer function of both pi speed and current controllers are given as,

$$
\begin{aligned}
& T f_{s p d}(S)=K_{P_{-} s p d}+\frac{K_{I_{-} s p d}}{S} \\
& T f_{c r n t}(S)=K_{P_{-} c r n t}+\frac{K_{I_{-} c r n t}}{S}
\end{aligned}
$$

Where, $K_{P_{-} s p d}$ and $K_{P_{-} c r n t}$ speaks to the proportional gain of the PI speed and current controller. $K_{I_{-} s p d}$ and $K_{I_{-} c r n t}$ speaks to the the integral gain of the PI speed and current controller respectively.

The execution of the SRM drive is eventually dictated by the optimal determination of the turn on and turns off switching angles which thusly minimize the torque ripple. With a specific end goal to restrain the torque pulsation, the generation of positive torque must be improved and the negative torque creation must be entirely stayed away from. Therefore by legitimate change of the turn on and turn off angles, the positive torque generation is started at the minimum inductance position. The creation of negative torque is maintained a strategic distance from by turn off the current prior and after that the maximum inductance position is come to. The proposed control structure of the SRM drive is outlined in the Fig. 1.

\section{ANFACO based gain parameter optimization}

The ACO is a meta-heuristic optimization method motivated by the genuine ants capacity to set up the most limited ways to their home from a sustenance source [21]. The movement of the ant depends on the quality of the pheromone trails on the ground. While hunting down the nourishment source by ants, the briefest way contains the pheromone trails. Subsequently, the vast majority of the ants gets pulled in and empowers with the goal that the briefest way is resolved. In this segment, ACO is utilized for enhancing the execution of the PI controller and for controlling the speed of the SRM alongside the turn on and turn off angles. The target work is resolved in light of the inputs and the gain parameters from the controller framework.

\section{Step 1: Initialization}

Initialize the ant's population $X_{i}$ and the number of ants $M$ are scattered randomly on each nodes. The gain parameters $K_{p}, K_{i}$, turn on $\phi_{o n}$ and turn off $\phi_{o f f}$ angles are also initiated. The accumulated strength of the pheromone on edge is initialized as $\sigma(j, k)$.

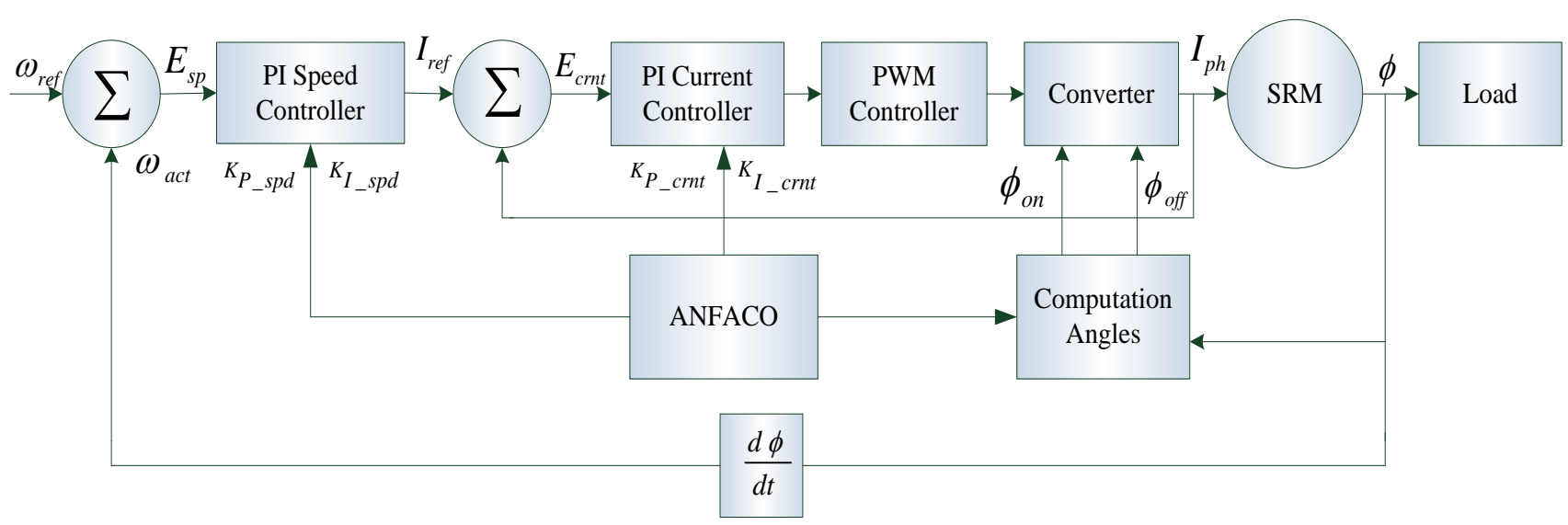

Figure. 1 Control structure of the SRM with the proposed technique 
The distance between the each pair of node $j$ and $k$ is represented as [22],

$$
\Delta J(j, k)=J_{j}-J_{k} \forall j, k
$$

Where $i=1,2, \ldots, M$ randomly selected from the feasible region.

\section{Step 2: Evaluation}

For every ant, the transition probability is figured for the choice of the best mix of short separation and vast pheromone levels by the accompanying connection,

$$
\rho_{n}(r, s)= \begin{cases}\frac{\sigma(j, k)[\Delta J(j, k)]^{\alpha}}{\sum_{u \in J_{n}(r)} \sigma(j, u)[\Delta J(j, u)]^{\alpha}} & \text { if } s \in J_{n}(j) \\ 0 & \text { or else, }\end{cases}
$$

By applying the above condition, the genuine ant $n$ situated at node $j$ picks its next node $k$. This determination is adjusted by permitting a probabilistic choice of the following node, which is given by,

$$
s= \begin{cases}\arg \max \left\{\sigma(j, u)[\Delta J(j, u)]^{\alpha}\right\} & \text { if } s \in J_{n}(j) \\ \rho_{n}(r, s) & \text { or else, }\end{cases}
$$

\section{Step 3: Fitness function}

Here, the fitness function is characterized to limit the speed error, current error and the torque ripples in view of the speed and current control system of the SRM. The fitness function is depicted in the accompanying condition as,

$$
\text { Fitness }=\operatorname{Min}\left\{f_{1}, f_{2}, f_{3}\right\}
$$

Where, $f_{1}=I S E_{\text {speed }}, f_{2}=I S E_{\text {crnt }}$, and $f_{3}=I S E_{\text {rip. }}$. These objective functions are achieved by satisfying the following constraints and the controller improves their behaviors based on their gain parameters.

$$
K_{p}^{\min } \leq K_{p} \leq K_{p}^{\max }
$$

$$
K_{I}^{\min } \leq K_{I} \leq K_{I}^{\max }
$$

$$
\phi_{\text {on }}^{\min } \leq \phi_{\text {on }} \leq \phi_{\text {on }}^{\max } \text { and } \phi_{\text {off }}^{\min } \leq \phi_{\text {off }} \leq \phi_{\text {off }}^{\max }
$$

Based on these constraints, the objective function is determined and the optimization is done by the following steps.

\section{Step 4: Local updating}

As indicated by the local updating rule, the pheromone level on the chose edge $\sigma(j, k)$ is refreshed when the ants move between the nodes. The ants will improve utilization of their pheromone trail data by the accompanying refreshing guideline,

$$
\sigma(j, k) \leftarrow(1-\partial) \cdot \sigma(j, k)+\partial \sigma_{o},
$$

Where, $\partial$ represents the decay parameter of the local pheromone $\partial \in(0,1)$, the initial value of pheromone is represented as $\sigma_{o}$ deposited on each edges. Until all the ants have built the complete solution, the trail is updated and then the best solution is recorded.

\section{Step 5: Global updating}

The global pheromone is updated once every one of the ants has developed a tour. The pheromone is updated by applying the accompanying global updating guideline,

$$
\sigma(j, k) \leftarrow(1-\gamma) \cdot \sigma(j, k)+\gamma \cdot \Delta \sigma(j, k),
$$

Where, $\gamma$ represents the decay parameter of the global pheromone $\gamma \in(0,1), \Delta \sigma(j, k)$ is used to reinforce the pheromone on the edges of the global solution which is given by,

$$
\begin{aligned}
& \Delta \sigma(j, k)=\sum_{n=1}^{m} \Delta \sigma_{n}(j, k), \\
& \Delta \sigma_{n}(j, k)= \begin{cases}\frac{Q}{\Delta J_{n}(j, k)} & \text { if } n \text {th ant useedge }(j, k) \\
0 & \text { and }(j, k) \in \text { globallybest tour }\end{cases} \\
& \text { orelse }
\end{aligned}
$$

Where, $\Delta \sigma_{n}(j, k)$ represents the pheromone quantity in the ant, $Q$ is the dependent parameter of the problem, $\Delta J_{n}(j, k)$ is the objective function 
computed based on the Eq. (16). The solution is repeated until the maximum iteration is reached.

\section{Step 6: Termination}

When the maximum iteration is achieved, terminate the condition and spare the best arrangement or else come back to step 2 to proceed with the above advances. The best arrangement is the optimal gain parameters $K_{p}$ and $K_{I}$ of the PI controller alongside the turn on and turn off switching angles. The gain parameters acquired by the above methodology is optimally anticipated utilizing the ANFIS technique. The plan of the ANFIS structure in light of the optimal gain parameter forecast is outlined in the accompanying area.

\subsection{ANFIS for predicting gain parameters}

In the proposed system, to improve the execution of the SRM drive, ANFIS method is used for the optimal expectation of gain parameters. ANFIS is a wise approach which joins the gain of both the ANN and fuzzy inference system (FIS) [23]. In view of the dynamic behavior of the SRM, the underlying estimations of both membership functions and rule base are acquired. At that point the parameters of the membership function are streamlined by the ANFIS procedure. Here, the ANFIS utilizes the rotor position and reference current as inputs and delivers the optimal current signal as the output. For the most part, the fuzzy rules are made in view of the two input variables $\mathrm{x} 1$ and $\mathrm{x} 2$ and one output variable $\mathrm{y}$ of the sugeno FIS. The rules are given by [24],

$$
\begin{aligned}
& \text { Rule 1: If } x_{1} \text { is } A_{2}, x_{2} \text { is } B_{1} \text {, } \\
& \text { then } y_{1}=p_{1} x_{1}+q_{1} x_{2}+r_{1} \\
& \text { Rule 2: If } x_{1} \text { is } A_{1}, x_{2} \text { is } B_{2}, \\
& \text { then } y_{2}=p_{2} x_{1}+q_{2} x_{2}+r_{2}
\end{aligned}
$$

Where, the consequent parameters of the ith rule are represented as $p_{1}, q_{1}, r_{l}$ and the linguistic labels are represented as $A_{i}$ and $B_{i}$.

The fundamental learning guideline of ANFIS is the back-propagation gradient decent which computes the error signal recursively from the output layer to the input nodes. Amid the learning system, the weights and bias related with the membership functions are balanced. The gradientdescendent system helps the computational work of the parameters obtaining and their modifications which demonstrates the decline of error esteem. The

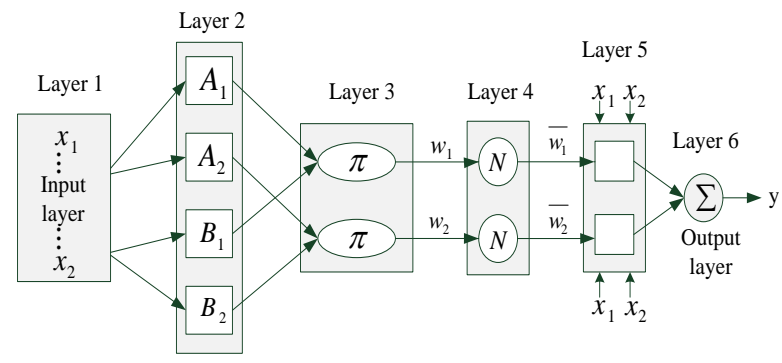

Figure. 2 ANFIS model structure

optimization routine may alter the parameters when the gradient is acquired and consequently the error gets limited.

\subsubsection{Learning strategy}

In this segment, the training dataset got from the ACO is then passed to the training algorithm. So the torque ripple is deciphered as error data for each reference current and the rotor position by the controller. The yield of the controller is then straightened out to limit the torque ripple of SRM. Until the point when the minimum torque ripples value, the procedure is rehashed. The learning process gets finished when the most extreme number of iteration is come to. Here, the hybrid technique such as back propagation and the mean squared error method optimizes the ANFIS process. At the point when the training procedure gets finished, the optimal control signal for the controller is created. The generated signal is then added to the phase current to create the new reference current. The structure of the proposed ANFIS is shown in Fig. 2.

\section{Results and discussion}

In this work, a control mechanism is proposed for the torque ripple minimization in light of ANFACO procedure which is equipped for giving both the speed and current control alongside the optimal selection of turn on and turns off switching angle. Here, a three phase $8 / 6 \mathrm{SRM}$ is considered and the proposed ANFACO based PI controller is actualized in MATLAB/Simulink stage. For assessing the execution of the speed, current and torque, the PI controllers are produced in the speed and current control loop. In view of the gain parameters of PI controller, the proposed system assesses the target work by limiting the ISE of speed, current and torque ripple. The optimal control signal is produced for the SRM by the proposed ANFACO system. The viability of the proposed strategy is tried and contrasted [20] and the current strategies, for example, ALO, NSGA-II and CMFG-RNN. 


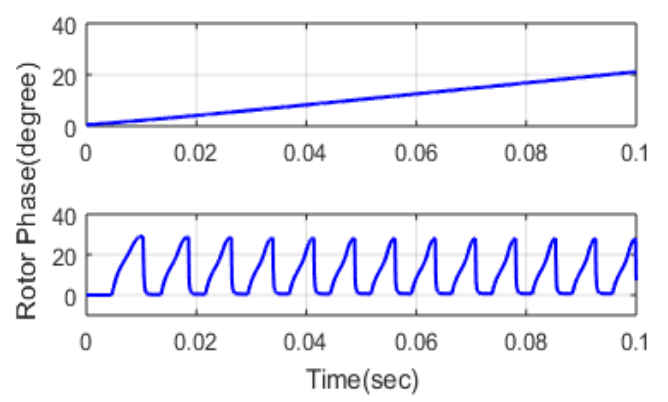

Figure. 3 Continuous and modulated signal of rotor position

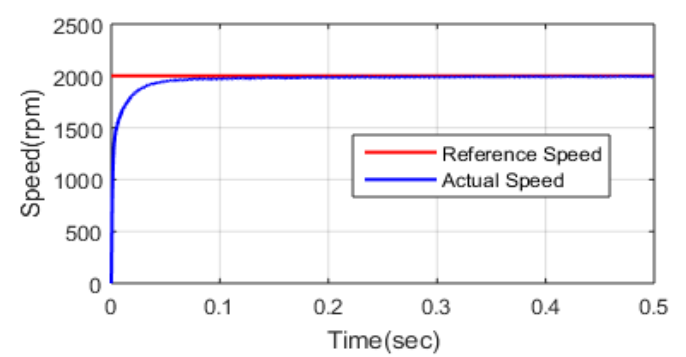

Figure. 4 Proposed speed at steady state condition

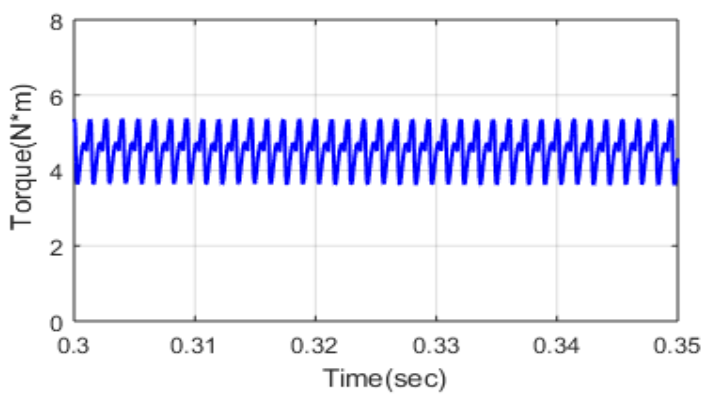

Figure. 5 Torque proposed under steady state condition

\section{A) Steady state performance of SRM with ANFACO}

In this segment, the execution of the proposed controller is broke down under the steady state condition. The parameters, for example, speed, current, rotor position, flux and torque are examined and contrasted with the distinctive systems. Here, the rotor position is considered for the time interval of $0.1 \mathrm{~s}$. The rotor position is continuously recognized and adjusted for a complete mechanical rotation, which is appeared in Fig. 3. Comparing to the optimal parameter the speed is followed with the reference speed under $0.5 \mathrm{~s}$ and the total torque is investigated for 0.3 to $0.35 \mathrm{~s}$ for a minimum objective function which is appeared in Figs. 4 and 5.

The total torque and phase current waveform under the steady state condition is taken at the time scale of $0.3-0.34 \mathrm{~s}$ by the proposed technique and the MFO technique is showed up in Fig. 6. The flux intensity controlled by the proposed method under the steady state performance gives better reaction and its adequacy is contrasted and the current systems as appeared in Fig. 7.

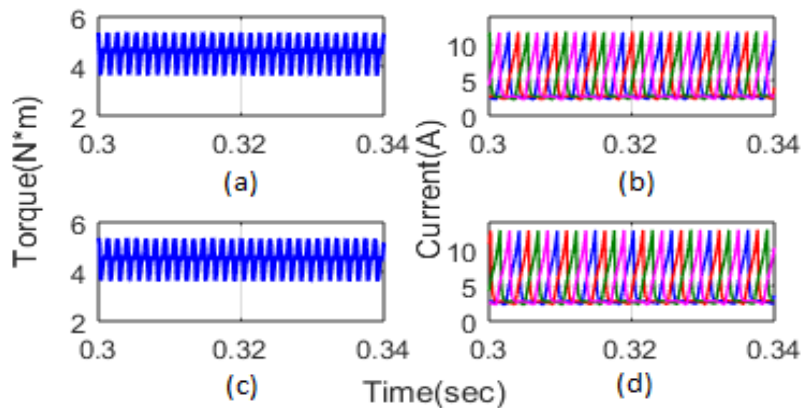

Figure. 6 (a) Proposed total torque, (b) proposed phase current, (c) total torque by MFO, and (d) phase current by MFO under steady state condition

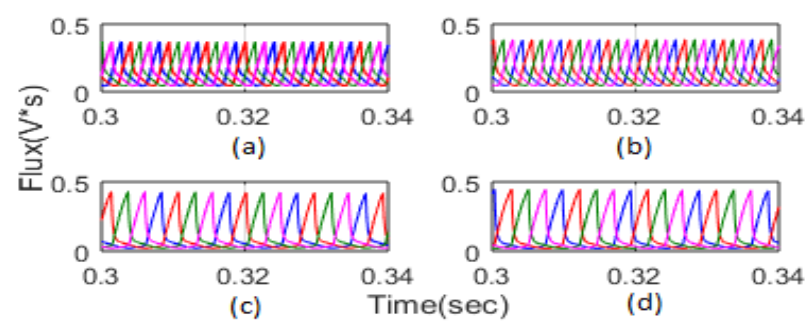

Figure. 7 Comparison of flux intensity with (a) Proposed, (b) CMFG-RNN, (c) NSGA-II, and (d) ALO

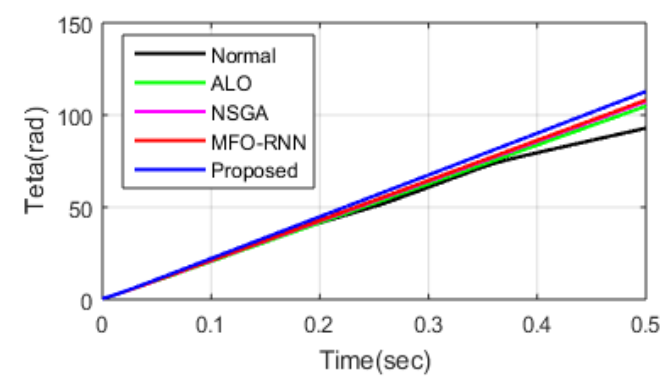

Figure. 8 Performance of switching angle with the various algorithms

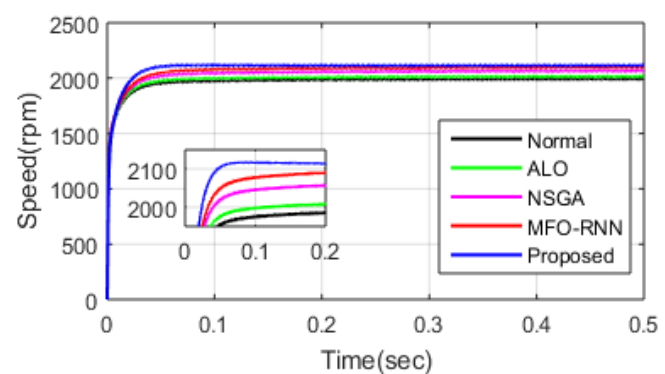

Figure. 9 Performance of speed tracking with the existing algorithms

The execution of the controller to the extent switching angles with the different algorithms is looked at in Fig. 8. From the figure, it is watched that the proposed procedure accomplishes better switching angles when differentiated and the current techniques. From the correlation, the proposed accomplishes superior of speed response and for the clarity, the response is zoomed between $0-0.2 \mathrm{~s}$ as showed up in Fig. 9. 


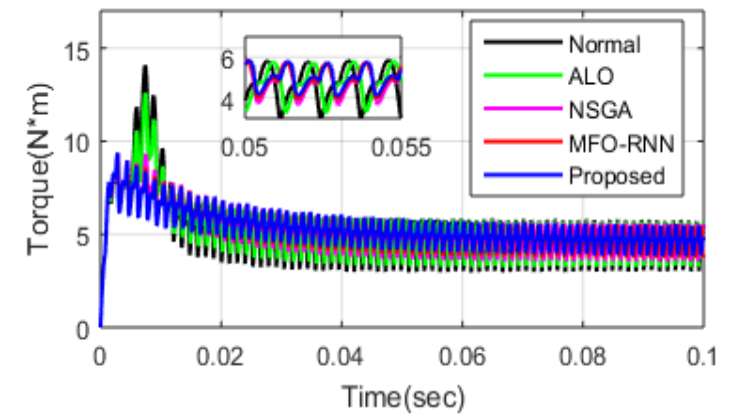

Figure. 10 Performance of torque with the existing techniques

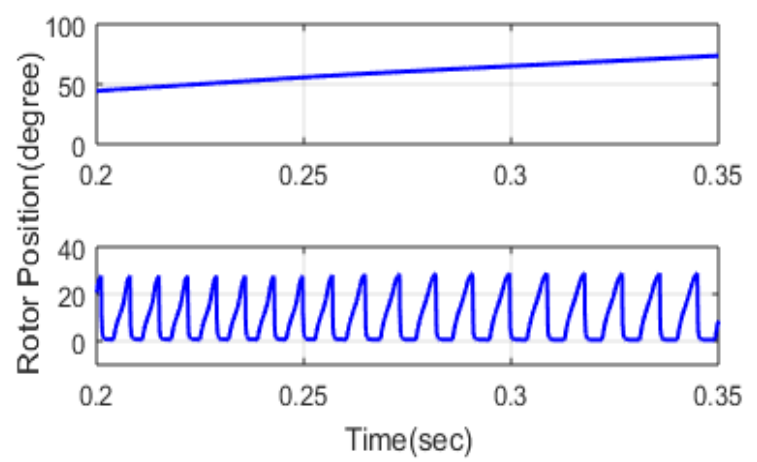

Figure. 11 Continuous and modulated signal of rotor position under step input condition

The execution of the output torque utilizing the proposed ANFACO technique gives preferable response signal over the current algorithm and the focused region between $0.05-0.055 \mathrm{~s}$ is showed up in Fig. 10. From the general execution examination, the proposed framework gives improved execution than the current calculation methods.

\section{B) Dynamic performance of SRM with ANFACO}

In this area, the execution of the proposed controller is inspected under the dynamic state condition, for instance, step response condition and variable response condition. The parameters, for example, speed, current, rotor position, flux ad torque are examined and contrasted with the different techniques. Here, the rotor position is considered for the time interval of $0.2-0.35 \mathrm{~s}$. The rotor position is perseveringly recognized and balanced for an entire mechanical rotation under the step input variation is appeared in Fig. 11.

Identifying with the optimal parameter the speed is followed with the reference speed under the step variation condition for $0.5 \mathrm{~s}$ for a minimum objective function which is appeared in Fig. 12. The total torque and current waveform is taken at the time scale of $0.3-0.34 \mathrm{~s}$ by the proposed technique and the MFO technique during the step variation is showed up in Fig. 13. The flux intensity managed by the proposed methodology under the dynamic performance gives better reaction and its reasonability is differentiated and the current strategies as showed up in Fig. 14.

The execution of the controller to the extent switching angles with the different algorithms is looked at in Fig. 15. The connection of speed tracking execution is performed using different algorithms is showed up in Fig. 16. Here, the step input variation happens between $0.25-0.35 \mathrm{~s}$ and the proposed achieves superior of speed response and amid the variation response is zoomed for clarity.

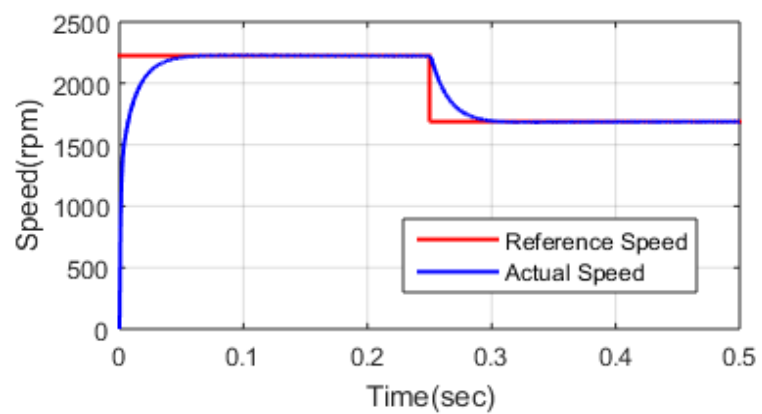

Figure. 12 Proposed speed at step input condition

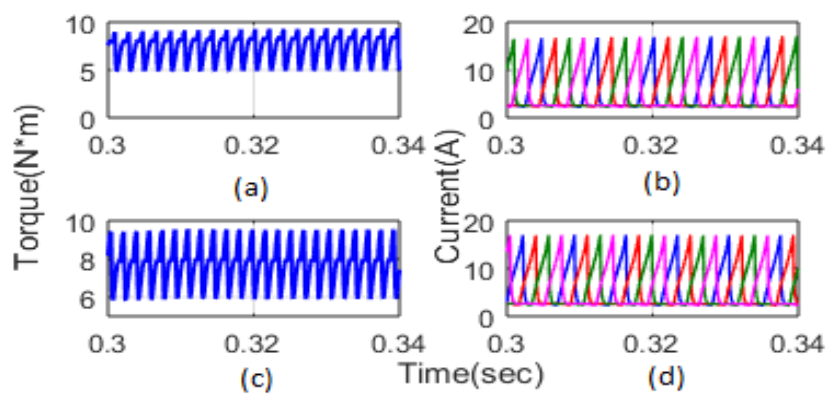

Figure. 13 (a) Proposed total torque, (b) proposed phase current, (c) total torque by MFO, and (d) phase current by MFO under step variation condition
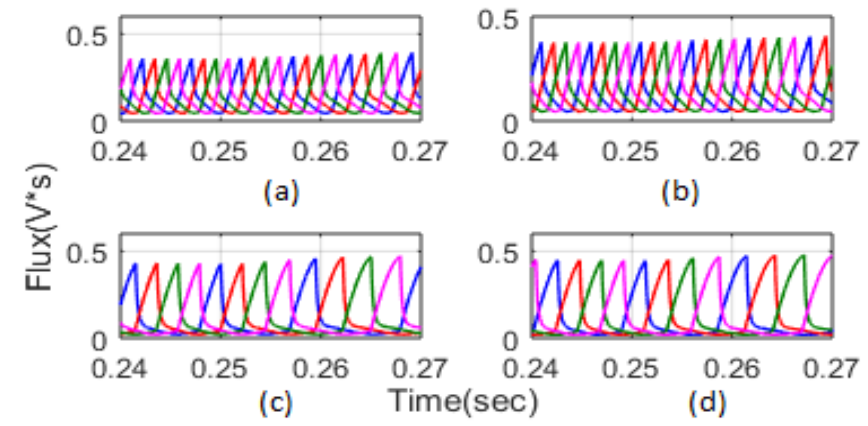

Figure. 14 Comparison of flux intensity with (a) Proposed, (b) CMFG-RNN, (c) NSGA-II, and (d) ALO during step variation condition 


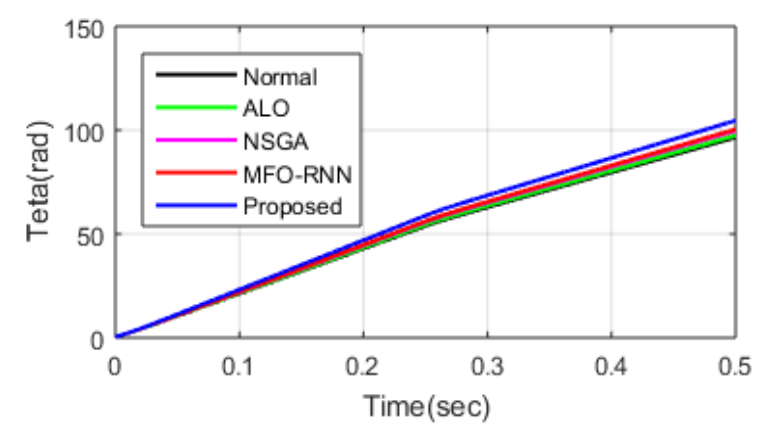

Figure. 15 Performance of switching angle with the various algorithms during step input variation

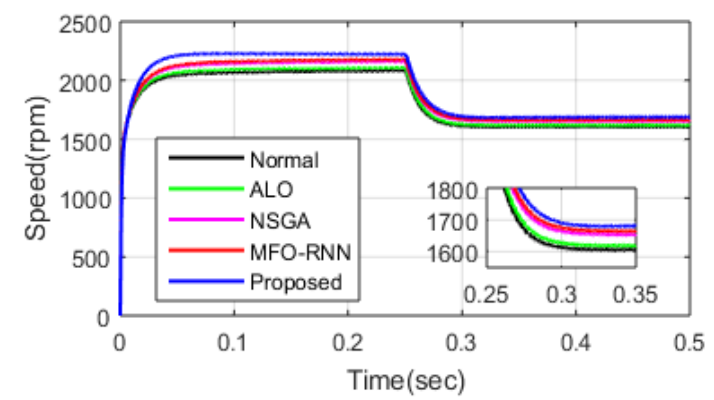

Figure. 16 Performance of speed tracking with the existing algorithms during step input variation

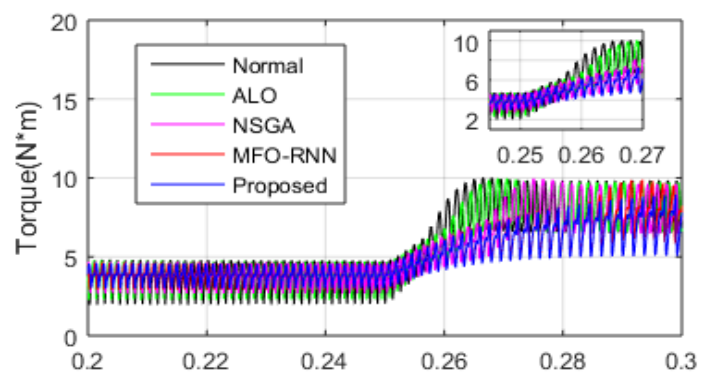

Figure. 17 Performance of torque with the existing techniques during step input variation

The execution of the output torque using the proposed ANFACO method and the current algorithms is appeared in Fig. 17. The torque variation is found in the region between $0.25-0.27$ and it shows that the proposed ANFACO procedure gives ideal response signal over the present methodologies.

The execution of the proposed controller is dismembered under the dynamic state condition of variable response condition. Here, the rotor position is considered for the time interval of $0.1-0.4 \mathrm{~s}$. The rotor position is reliably perceived and balanced for an entire mechanical rotation under the variable input variation is appeared in Fig. 18 (a) and (b). Contrasting with the optimal parameter, the speed is followed with the reference speed under the variable input condition for $0.5 \mathrm{~s}$ for a minimum objective function which is appeared in Fig. 19. The total torque and current waveform is taken at the time scale of $0.34-0.38 \mathrm{~s}$ by the proposed technique and the moth flame optimization (MFO) technique during the variable input condition is showed up in Fig. 20.

The flux intensity controlled by the proposed system gives better reaction during the variable input condition and its practicality is contrasted and the current procedures as appeared in Fig. 21. By applying the proposed method, the gain parameters of the speed controller, current controller and the turn on and turn off switching angles are ideally dictated by restricting the objective function. The execution of the controller in regards to switching angles with the different algorithms is thought about in Fig. 22. The correlation of speed following execution is performed using different algorithms is showed up in Fig. 23.

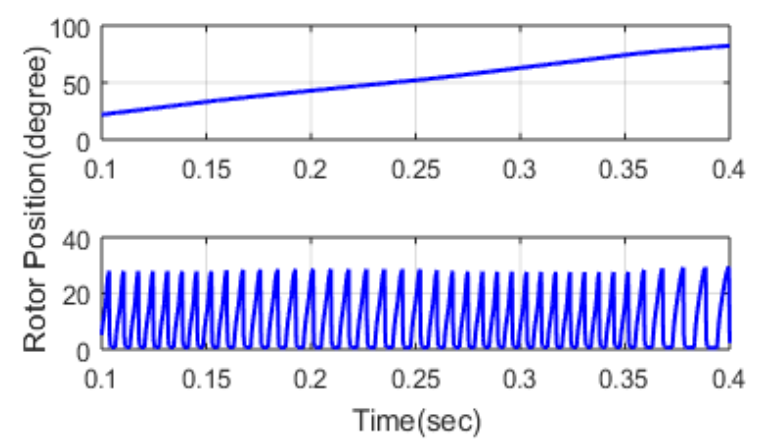

Figure. 18 Continuous and modulated signal of rotor position under variable input condition

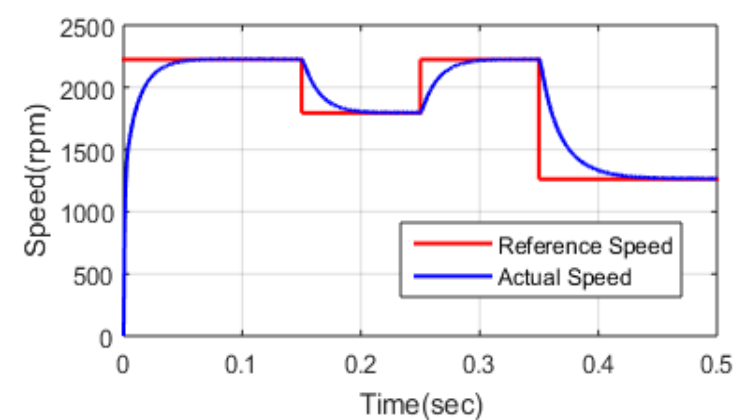

Figure. 19 Proposed speed at variable input condition

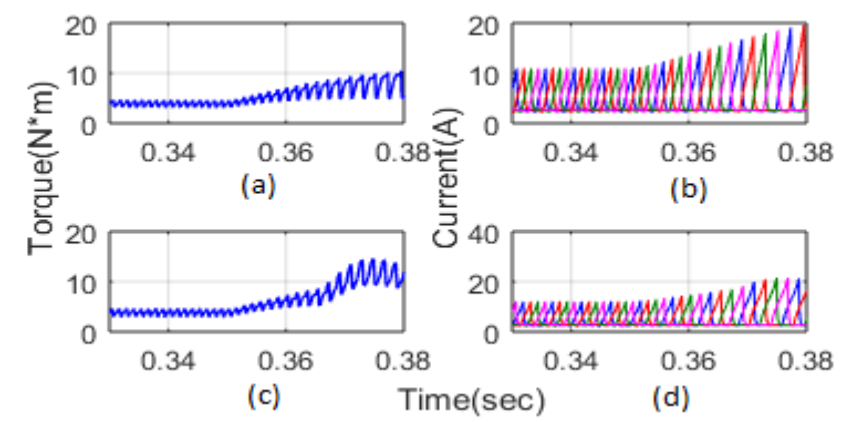

Figure. 20 (a) Proposed total torque, (b) proposed phase current, (c) total torque by MFO, and (d) phase current by MFO for variable input condition 


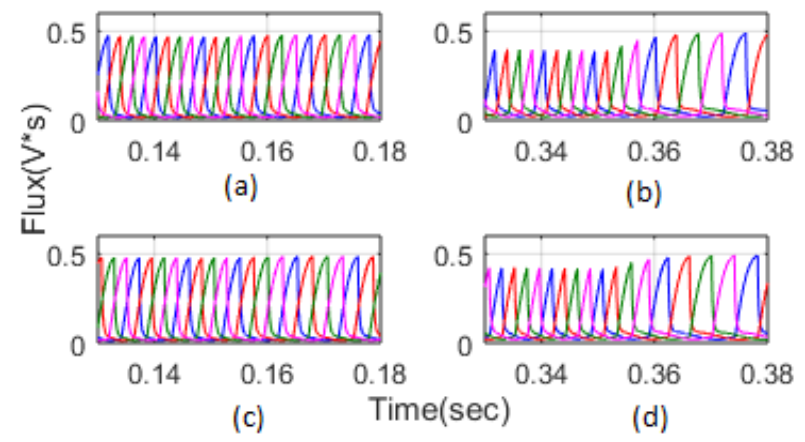

Figure. 21 Comparison of flux intensity with (a) Proposed,

(b) CMFG-RNN, (c) NSGA-II and (d) ALO during variable input condition

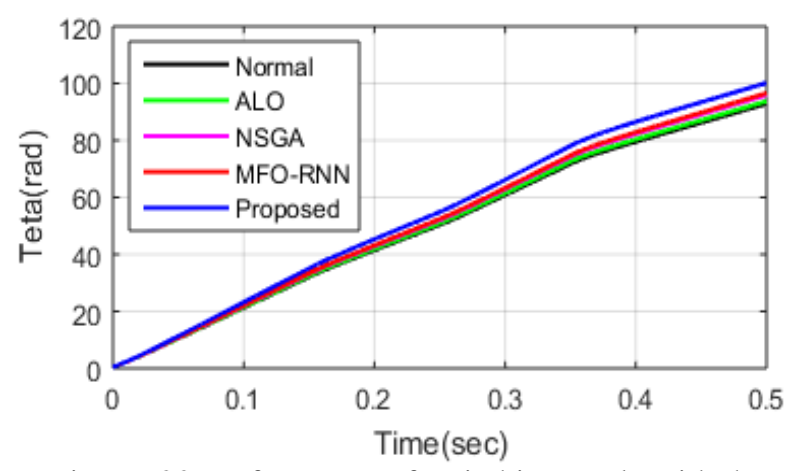

Figure. 22 Performance of switching angle with the various algorithms during variable input condition

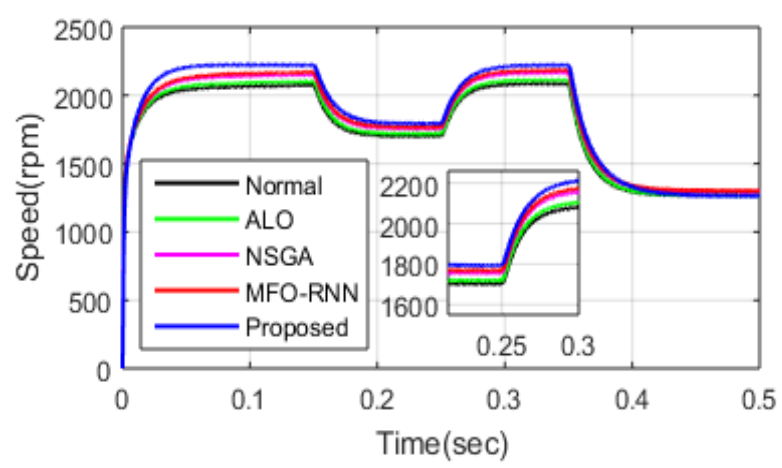

Figure. 23 Performance of speed tracking with the existing algorithms during variable input condition

Here, the variable input condition occurs between $0.25-0.3 \mathrm{~s}$ and the proposed achieves elite of speed response and amid the variation, response is zoomed for clearness. The execution of the output torque using the proposed ANFACO procedure and the current algorithms is appeared in Fig. 24. The torque variation is found in the region between 0.240.26 and it shows that the proposed ANFACO method gives preferred response signal over the current algorithm. From the general execution examination, the proposed procedure gives enhanced execution than the present techniques. By using the proposed strategy, the torque ripples get diminished and in this way the execution of the SRM gets extended suitably.

\subsection{Statistical analysis}

The reasonability of the proposed method is surveyed by the measurable examination of optimal gain parameters of the PI controller and organized in table.1. By using the proposed controller, powerful optimal gain parametesrs has been accomplished to limit the torque ripples.

From Table 1, it has been watched that the torque ripples are basically decreased by the proposed system than the present techniques. The execution of proposed the extent that the objective function is looked at in Table. 2. Here, the mean, median and standard deviations are obtained by the proposed and the current methods. From the examination, the authenticity of the proposed technique is settled. From the general reenactment occurs, the proposed technique is sensible in tackling the torque ripple issues by quick response of rise time, settling time and overshoot time.

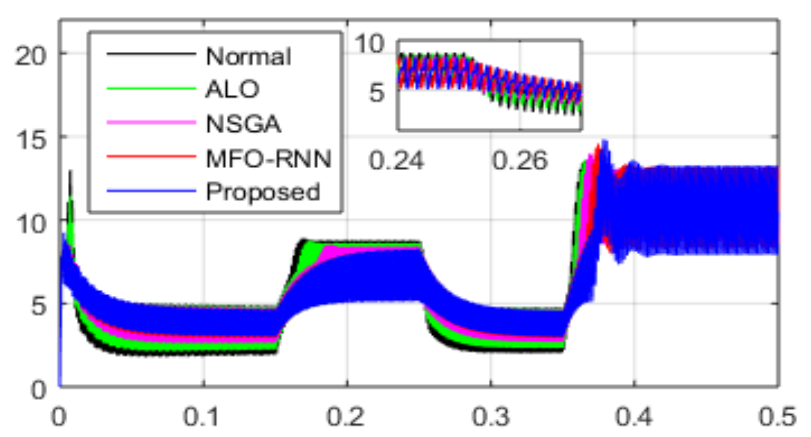

Figure. 24 Performance of torque with the existing techniques during variable input condition

Table 1. Optimal parameters of proposed PI controller

\begin{tabular}{|c|c|c|c|c|c|c|c|c|c|}
\hline Parameters/Techniques & \multicolumn{3}{|c|}{ NSGA-II } & \multicolumn{3}{c|}{ CMFG-RNN } & \multicolumn{3}{c|}{ ANFACO } \\
\hline PI Controller & Speed & Current & $\begin{array}{c}\text { Torque } \\
\text { ripple }\end{array}$ & Speed & Current & $\begin{array}{c}\text { Torque } \\
\text { ripple }\end{array}$ & Speed & Current & $\begin{array}{c}\text { Torque } \\
\text { ripple }\end{array}$ \\
\hline$K_{p}$ & 7.742 & 6.671 & 9.096 & 7.058 & 5.834 & 8.264 & 6.938 & 5.3261 & 7.3254 \\
\hline$K_{I}$ & 0.360 & 0.9322 & 0.8107 & 0.342 & 0.872 & 0.716 & 0.325 & 0.7782 & 0.6541 \\
\hline$\phi_{\text {on }}$ & 0.177 & 0.1943 & 0.2012 & 0.154 & 0.164 & 0.184 & 0.132 & 0.1457 & 0.1251 \\
\hline$\phi_{\text {off }}$ & 0.736 & 0.7301 & 0.7264 & 0.687 & 0.682 & 0.687 & 0.604 & 0.624 & 0.615 \\
\hline
\end{tabular}


Table 2. Performance comparison of proposed with existing techniques

\begin{tabular}{|c|c|c|c|}
\hline Parameters/Techniques & \multicolumn{3}{|c|}{ Fitness function } \\
\hline Methods & Mean & Median & $\begin{array}{c}\text { Std. } \\
\text { deviation }\end{array}$ \\
\hline NSGA-II & 0.7947 & 0.5632 & 0.2913 \\
\hline CMFG-RNN & 0.7242 & 0.5254 & 0.2047 \\
\hline ANFACO & 0.7080 & 0.4981 & 0.1954 \\
\hline
\end{tabular}

\section{Conclusion}

The speed control of SRM by ANFACO system for the torque ripple minimization is proposed in this paper. The proposed systems decide the ideal parameters of speed controller, current controller close by the turn on and turn off switching angles. By constraining the objective function of ISE of speed, current and torque ripple, the optimal gains are resolved. The proposed strategy is executed in the MATLAB/Simulink Platform and its execution is surveyed. The displays of the proposed procedure is evaluated by dissecting the parameters, for example, torque, current, speed with turn on and turn off switching angles. Remembering the true objective to exhibit the suitability, the results procured by the proposed technique is differentiated and endorsed and existing strategies like ALO, NSGA-II and CMFG-RNN frameworks. The simulation results are taken under the steady state and the dynamic performance conditions. In both the performance conditions, the results reveal that the proposed ANFACO controller are suitable in constraining the torque ripple with the optimal switching angles and achieves quick quick response of rise time, settling time and overshoot time. Therefore, the dynamic execution of the SRM drive is upgraded enough.

\section{References}

[1] E. S. Prasad and B. S. Ram, "Multi-Objective Optimized Controller for Torque Ripple Minimization of Switched Reluctance Motor Drive System", Indian Journal of Science and Technology, Vol. 9, No. 20, pp. 1-10, 2016.

[2] Z. Zhu, B. Lee, L. Huang, and W. Chu, "Contribution of Current Harmonics to Average Torque and Torque Ripple in Switched Reluctance Machines", IEEE Transactions on Magnetics, Vol . 53, No. 3, pp. 1-1, 2016.

[3] Y. Cho, Y. Bak, and K. Lee, "Torque-Ripple Reduction and Fast Torque Response Strategy for Predictive Torque Control of Induction Motors", IEEE Transactions on Power Electronics, Vol. 33, No. 3, pp. 1-1, 2017.
[4] H. Huang, K. Hu, and C. Liaw, "Switch-mode rectifier fed switched-reluctance motor drive with dynamic commutation shifting using DClink current", IET Electric Power Applications, Vol. 11, No. 4, pp. 640-652, 2017.

[5] T. V. Mahendiran, K. Thanushkodi, and P. Thangam, "Speed Control of Switched Reluctance Motor Using New Hybrid Particle Swarm Optimization", Journal of Computer Science, Vol.8, No.9, pp.1473-1477, 2012.

[6] H. Huang, K. Hu, and C. Liaw, "Switch-mode rectifier fed switched-reluctance motor drive with dynamic commutation shifting using DClink current", IET Electric Power Applications, Vol. 11, No. 4, pp. 640-652, 2017.

[7] M. Siami, D. Khaburi, and J. Rodriguez, "Torque Ripple Reduction of Predictive Torque Control for PMSM Drives With Parameter Mismatch", IEEE Transactions on Power Electronics, Vol. 32, No. 9, pp. 7160-7168, 2017.

[8] A. Shahabi, A. Rashidi, M. Afshoon, and S. Saghaian Nejad, "Commutation angles adjustment in SRM drives to reduce torque ripple below the motor base speed", Turkish Journal of Electrical Engineering \& Computer Sciences, Vol. 24, No. 2, pp. 669-682, 2016.

[9] A. Abosh, Z. Zhu, and Y. Ren, "Reduction of Torque and Flux Ripples in Space Vector Modulation-Based Direct Torque Control of Asymmetric Permanent Magnet Synchronous Machine", IEEE Transactions on Power Electronics, Vol. 32, No. 4, pp. 2976-2986, 2017.

[10] G. Foo and X. Zhang, "Constant Switching Frequency Based Direct Torque Control of Interior Permanent Magnet Synchronous Motors With Reduced Ripples and Fast Torque Dynamics", IEEE Transactions on Power Electronics, Vol. 31, No. 9, pp. 6485-6493, 2016.

[11] S. Yao and W. Zhang, "A Simple Strategy for Parameters Identification of SRM Direct Instantaneous Torque Control", IEEE Transactions on Power Electronics, Vol. 33, No. 4, pp. 3622-30, 2017.

[12] D. Mohan, X. Zhang, and G. Foo, "A Simple Duty Cycle Control Strategy to Reduce Torque Ripples and Improve LowSpeed Performance of a Three-Level Inverter Fed DTC IPMSM Drive", IEEE Transactions on Industrial Electronics, Vol. 64, No. 4, pp. 2709-2721, 2017. 
[13] W. Chen, W. Dai, Z. Wang, G. Zhang, Y. Yan, and C. Xia, "Optimal space vector pulse width modulation strategy of neutral point clamped three-level inverter for output current ripple reduction", IET Power Electronics, Vol. 10, No. 12, pp. 16381646, 2017.

[14] Z. Zhu, B. Lee, L. Huang, and W. Chu, "Contribution of Current Harmonics to Average Torque and Torque Ripple in Switched Reluctance Machines", IEEE Transactions on Magnetics, Vol. 53, No. 3, pp. 1-1, 2016.

[15] N. Saha, A. Panda, and S. Panda, "Speed control with torque ripple reduction of switched reluctance motor by many optimizing liaison technique", Journal of Electrical Systems and Information Technology, Vol. 1, No. 1, pp. 1-10, 2017.

[16] C. Labiod, K. Srairi, B. Mahdad, and M. Benbouzid, "A novel control technique for torque ripple minimization in switched reluctance motor through destructive interference", Electrical Engineering, Vol. 1, No. 1, pp. 1-10, 2017.

[17] X. Deng, B. Mecrow, H. Wu, and R. Martin, "Design and Development of Low Torque Ripple Variable-Speed Drive System with Six-Phase Switched Reluctance Motors", IEEE Transactions on Energy Conversion, Vol. 33, No. 1, pp. 420- 429, 2017.

[18] H. Zhang and S. Wang, "Topology Optimization of Rotor Pole in Switched Reluctance Motor for Minimum Torque Ripple", Electric Power Components and Systems, Vol. 45, No. 8, pp. 905-911, 2017.

[19] C. Li, G. Wang, Y. Li, and A. Xu, "An improved finite-state predictive torque control for switched reluctance motor drive", IET Electric Power Applications, Vol. 12, No. 1, pp. 144-151, 2018.

[20] L. Kalaivani, P. Subburaj, and M. Willjuice Iruthayarajan, "Speed control of switched reluctance motor with torque ripple reduction using non-dominated sorting genetic algorithm (NSGA-II)", International Journal of Electrical Power \& Energy Systems, Vol. 53, No. 12, pp. 6977, 2013.
[21] Y. Chang, C. Chang, C. Tao, H. Lin, and J. Taur, "Fuzzy sliding-mode control for ball and beam system with fuzzy ant colony optimization", Expert Systems with Applications, Vol. 39, No. 3, pp. 3624-3633, 2012.

[22] H. Duan, D. Wang, and X. Yu, "Novel Approach to Nonlinear PID Parameter Optimization Using Ant Colony Optimization Algorithm", Journal of Bionic Engineering, Vol. 3, No. 2, pp. 73-78, 2006.

[23] K. Lakshmanan, S. Perumal, and W. Mariasiluvairaj, "Artificial Intelligencebased control for torque ripple minimization in switched reluctance motor drives", Acta Scientiarum. Technology, Vol. 36, No. 1, pp. 33-40, 2013.

[24] B. Sen, U. Mandal, and S. Mondal, "Advancement of an intelligent system based on ANFIS for predicting machining performance parameters of Inconel 690 - A perspective of metaheuristic approach", Measurement, Vol. 109, No. 10, pp. 9-17, 2017. 